
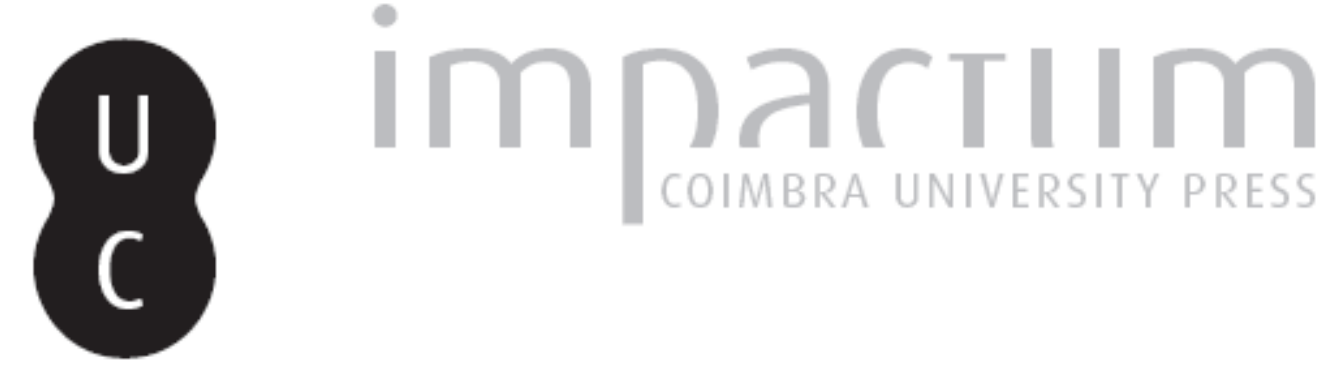

\title{
¿Puede ser considerado el flaminado cívico el honor de mayor prestigio dentro de las carreras locales conocidas en Lusitania?
}

Autor(es): $\quad$ González Herrero, Marta

Publicado por: Faculdade de Letras da Universidade de Coimbra

URL

persistente:

URI:http://hdl.handle.net/10316.2/37664

DOI:

DOI:http://dx.doi.org/10.14195/1647-8657_41_2

Accessed : $\quad$ 26-Apr-2023 14:27:50

A navegação consulta e descarregamento dos títulos inseridos nas Bibliotecas Digitais UC Digitalis, UC Pombalina e UC Impactum, pressupõem a aceitação plena e sem reservas dos Termos e Condições de Uso destas Bibliotecas Digitais, disponíveis em https://digitalis.uc.pt/pt-pt/termos.

Conforme exposto nos referidos Termos e Condições de Uso, o descarregamento de títulos de acesso restrito requer uma licença válida de autorização devendo o utilizador aceder ao(s) documento(s) a partir de um endereço de IP da instituição detentora da supramencionada licença.

Ao utilizador é apenas permitido o descarregamento para uso pessoal, pelo que o emprego do(s) título(s) descarregado(s) para outro fim, designadamente comercial, carece de autorização do respetivo autor ou editor da obra.

Na medida em que todas as obras da UC Digitalis se encontram protegidas pelo Código do Direito de Autor e Direitos Conexos e demais legislação aplicável, toda a cópia, parcial ou total, deste documento, nos casos em que é legalmente admitida, deverá conter ou fazer-se acompanhar por este aviso.

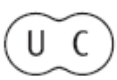




\section{CONIMBRIGA}

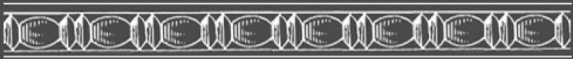

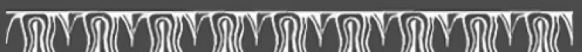
2

INSTITUTO DE ARQUEOLOGIA

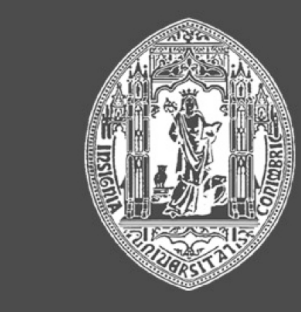

VOLUME XLI - 2002

F A C U L D A E D E LETRAS UNIVERSIDADE DE COIMBRA 
Marta GonZÁlez HerRero

Universidad de Oviedo

¿PUEDE SER CONSIDERADO EL FLAMINADO CÍVICO EL HONOR DE MAYOR PRESTIGIO DENTRO DE LAS CARRERAS LOCALES CONOCIDAS EN LUSITANIA?

"Conimbriga" XLI (2002) p. 39-61

RESUMEN: A partir de los cursus honorum que incluyen un flaminado cívico protagonizados por las elites de Lusitania, se reflexiona sobre la metodología a utilizar para estudiar las carreras locales grabadas sobre documentación epigráfica. La autora plantea la imposibilidad de valorar el prestigio de los honores, en función del orden cronológico en que éstos son recibidos. Así mismo recomienda considerar únicamente las carreras finalizadas para establecer cuál es la función de culminación.

RÉSUMÉ: À partir des cursus honorum qui renferment un flaminat civique parcourus par les élites de Lusitanie, on réfléchit sur la méthodologie pour étudier les "carrières politiques" gravées sur des documents épigraphiques. L'auteur pose l'impossibilité d'évaluer le prestige des honores en fonction de l'ordre chronologique de l'obtention et raccommande considérer uniquement les cursus finis pour déterminer l'honor culminant dans les carrières. 
(Página deixada propositadamente em branco) 


\section{¿PUEDE SER CONSIDERADO EL FLAMINADO CÍVICO EL HONOR DE MAYOR PRESTIGIO DENTRO DE LAS CARRERAS LOCALES CONOCIDAS EN LUSITANIA?}

Recientemente J. A. Delgado Delgado publicó el corpus constituido por todos aquellos sacerdotes y sacerdotisas que desempeñaron sus funciones en el ámbito cívico, dentro de la provincia romana de Lusitania $^{1}$. Este trabajo nos interesó especialmente, por su relación con nuestro estudio sobre la promoción social protagonizada por las elites del poder lusitanorromanas ${ }^{2}$, de las que naturalmente formaron parte los titulares de sacerdocios.

El catálogo epigráfico elaborado por el autor es ciertamente exhaustivo. Únicamente hemos echado en falta a dos sacerdotes: Iconius, un haruspex conocido por un epígrafe procedente de Caesarobriga ${ }^{3}$, y un pontífice anonymus que aparece mencionado en uno hallado en Emerita Augusta. La confusa traditio de este último documento explica por sí misma su ausencia en dicho corpus, por lo que aprovecharemos esta ocasión para confirmar la existencia del pontífice ${ }^{4}$.

El sacerdote es mencionado en un fragmento hallado en Mérida, sobre el que L. García Iglesias distinguió los siguientes caracteres grabados 5 :

$$
\begin{aligned}
& {[-] \text { M.f. Pap. }} \\
& {[-] \text { uir prae[-] }}
\end{aligned}
$$

1 "Los sacerdotes de rango local de la provincia romana de Lusitania", Conimbriga, 39, 2000, p. 107-152.

2 M. González Herrero (en prensa, formato CD-R).

3 CIL II, 898.

4 Nosotros lo consideramos incertus en el trabajo citado en not. 2.

5 ERAE, 486. 
En su estudio sobre los magistrados de Hispania romana, L. A. Curchin indicó que la lectura del final de esta inscripción estaba incompleta, sin ofrecer otro tipo de información ${ }^{6}$. El autor no sólo identificó al personaje como duumuir y praefectus, sino que también incluyó el pontificado entre los honores que integraban su cursus honorum. Por su parte, J. C. Saquete Chamizo ${ }^{7}$, señaló que L. A. Curchin también había planteado restituir la edilidad, aunque no había letras en la inscripción para hacerlo.

Con el propósito de comprobar una lectura que a partir de estas escuetas referencias se presentaba confusa, contactamos por correo electrónico con J. L. Ramírez Sádaba, quien atendiendo rápidamente nuestra demanda nos comunicó que no disponía de fotografía de la inscripción. Como el epígrafe se encuentra depositado en el Museo Nacional de Arte Romano de Mérida ${ }^{8}$, nos dirigimos a esta institución sin que hasta hoy hayamos recibido respuesta alguna. Finalmente, el propio L. García Iglesias tuvo la amabilidad de facilitarnos una fotografía de calidad, sobre la que hemos podido confirmar que en la última línea se leen con claridad cuatro letras de la palabra pontifex (fig. 1). Hemos restituido el texto del siguiente modo:

$$
\begin{aligned}
& {[-] M(\text { arcii) f(ilius) Pap }(\text { iria })[-]} \\
& {[-I I] \text { uir }(\text { duumuir }) \text { prae }[f(\text { ectus }) \text { fabrum?] }} \\
& {[- \text { pon }] \text { tife }[x-]}
\end{aligned}
$$

Aclarada esta cuestión, trataremos la que pretendemos abordar en este trabajo. En el estudio realizado por J. A. Delgado Delgado al que hemos aludido más arriba, llamó nuestra atención que, habiendo manejado la misma documentación epigráfica, hubiéramos llegado a conclusiones tan divergentes a la hora de valorar el lugar que ocupó el flaminado cívico dentro de los cursus protagonizados por los honorati en las ciudades de Lusitania. Para él, el flaminado sería "el cargo probablemente más prestigioso de cuantos ofrecían los cursus públicos de las ciudades lusitanas, superando en ello incluso a la principal

\footnotetext{
6 LMRS, 341.

7 1997, p. 118.

8 № de inventario 8547 .
} 
magistratura, el duovirado" 9 . En nuestra opinión, "los sacerdocios cívicos representaban un honor más a acumular en el cursus honorum, dentro del cual se insertaban en orden indistinto" ${ }^{10}$.

Esta disparidad en las conclusiones nos animó a revisar la metodología utilizada tanto en su trabajo como en el nuestro.

Al estudiar las carreras protagonizadas por los flamines cívicos que actuaron en ciudades lusitanas, J. A. Delgado Delgado aclara ${ }^{11}$ que acepta el orden directo de grabación de todos los cursus, básandose en que la secuencia cronológica de ejercicio de los honores es respetada en los que se puede determinar con certeza o mucha probabilidad: los protagonizados por Aponius Capito (HAE, 2641), Cn. Cornelius Cn.f. Pap. Seuerus (ERAE, 95), Q. Iulius Q. f. Gal. Plotus (EOlis., 41), C. Pompeius L.f. Pap. Priscus (ERAE, 112), [-Bo]chus (IRCP, 189) ${ }^{12}$ y [-] M.f. Ser. Modestus (ERAE, 108).

Tras analizar los cursus, el autor realiza dos constataciones a partir de las que concluye que el flaminado era posiblemente el honor de mayor prestigio dentro de las carreras locales conocidas en Lusitania ${ }^{13}$ :

- "En las catorce carreras en las que están presentes el flaminado y el duovirado, la magistratura precedió cronológicamente en doce ocasiones al sacerdocio".

- "El flaminado constituyó el colofón de diez de las once carreras locales".

Repasamos a continuación las catorce carreras en las que conviven un flaminado cívico y el duunvirato. Incluimos el lugar de procedencia de los epígrafes sobre los que fueron grabadas, su referencia bibliográfica más accesible, la secuencia de grabación de los honores y el grado de seguridad a la hora de establecer el orden de ejercicio de éstos.

9 Conimbriga, 39, 2000, p. 120.

10 M. González Herrero, p. 595 (en prensa, formato, CD-R).

11 Conimbriga, 39, 2000, p. 118, not. 23.

12 Aunque carece de importancia para la cuestión que nos ocupa, pensamos que los honores grabados sobre la placa conmemorativa de la construcción que L. Cornelius L. f. Gal. Bocchus financió en Salacia, vienen dados en orden inverso, M. González Herrero, Aquila Legionis, 2, 2002, p. 33-57.

13 Conimbriga, 39, 2000, p. 120. 


\section{CARRERAS EN LAS QUE CONVIVEN FLAMINADO Y DUUNVIRATO}

\section{1. [-] M.f. SER. MODESTUS}

\section{Procedencia del epígrafe: Mérida}

Referencias bibliográficas: ERAE, 108; LMRS, 348; J. C. Saquete Chamizo, 1997, p. 117, 130, lám. VI. 2, p. 212

Cursus honorum, según orden de grabación:

1ำ flamen Diui Augusti

$2^{\mathrm{o}}$ duumuir

$3^{\text {o }}$ praefectus fabrum

$4^{\circ}$ flamen prouinciae Lusitaniae

Reconstrucción de la secuencia de ejercicio de los honores: segura (orden directo)

La adscripción del magistrado a la tribu Sergia revela que su familia no era originaria de Emerita Augusta, ciudad donde actuó como flamen Diui Augusti y ocupó el duunvirato.

Una primera posibilidad es que el ordo de la colonia le hubiera reconocido el estatuto de incolatus, sin que [-] M. f. Ser. Modestus adquiriera la ciuitas local. Es posible que en el espacio perdido en la línea segunda (fig. 2) estuviera indicada su condición de incola o la origo $^{14}$.

También puede tratarse de un ciues adlectus en Emerita Augusta o directamente integrado en el ordo, institución con poder legal para la adlectio de decuriones ${ }^{15}$. En este caso a [-] M. f. Ser. Modestus se le habría otorgado la ciuitas en la capital de Lusitania, cuando ya disfrutaba de la ciudadanía romana. Conviene aclarar que esta segunda ciudadanía no sustituía a la primera, es decir, no afectaba al origen familiar, lo que explica que el magistrado conservara la tribu Sergia correspondiente al lugar donde él mismo o alguno de sus antepasados

14 Como acontece en los epígrafes que mencionan a los incolae miembros de los ordines decurionum constituidos en ciudades de la Bética: un Patriciensis en Axati (CIL II, 1055), un Arsensis en Iulipa (ILER, 6845) y un Patriciensis domo Sucaeloni en Corduba (ILER, 5505).

15 F. Jacques, 1984, p. 576-579. 
habían adquirido la ciuitas romana ${ }^{16}$. Por tanto, no podemos descartar que [-] M.f. Ser. Modestus fuera un ciudadano procedente de Emerita Augusta descendiente de un adlectus.

Aunque resulta imposible determinar de qué ciudad era originaria su familia, la tribu Sergia nos remite a Hispania y su condición de flamen de Lusitania a un lugar dentro de esta provincia. Dicha tribu está documentada en las colonias lusitanas de Norba ${ }^{17}$, Metellinum ${ }^{18}$ y Scallabis ${ }^{19}$.

Tampoco es descartable que [-] M. f. Ser. Modestus fuera un foráneo que hubiera establecido su domicilium en territorio de Emerita Augusta, requisito exigido a todo decurión ${ }^{20}$. Pensamos que esta posibilidad es menos probable, ya que en este caso le hubiera resultado mucho más difícil obtener los honores cívicos y religiosos.

\section{APONIUS CAPITO}

Procedencia del epígrafe: Santarém o lugar próximo

Referencias bibliográficas: $H A E, 2641 ; \mathrm{M} .^{\mathrm{a}}$ das D. G. da Cruz, Arqueologia, 14, 1986, p. 115-121; LMRS, 332; RAP, 46; J. C. Saquete Chamizo, 1997, p. 116

\section{Cursus honorum, según orden de grabación:}

$1^{\mathrm{o}}$ duumuir Col. Aug. I. [Em.]

$2^{\circ}$ praefectus fabrum

$3^{\text {o }}$ flamen Col. Aug. I. [Em.]

4o flamen prouinciae Lusitaniae Diui Augusti Diuae Augustae

Reconstrucción de la secuencia de ejercicio de los honores: segura (orden directo)

J. M. Garcia ${ }^{21}$ identifica el gentilicio de Capito como Aponius y restituye el nombre de la colonia donde este personaje ocupó el

16 Recordemos que la tribu se transmite por filiación paterna y que el cambio de origo y la transferencia de tribu que ocasionaba requerían la intervención del poder central, I. Thomas, 1996, cap. IV.

17 ILS, 2098, CIL XIII, 5975 у HAE, 761.

18 J. Salas Martín, Veleia, 4, 1987, p. 135-138.

19 CIL II, $326=5229$ y CIL VIII, 3182.

20 Lex Tar., 26 y lex Urs., 91.

21 RAP, 46. 
flaminado y el duunvirato como Col(oniae) Aug(ustae) I(uliae) [S(callabis)] (Fig. 3) 22 .

Por lo que se refiere a la denominación de Scallabis, hemos de señalar que no vemos la necesidad de precisar dónde Capito había recibido los honores cívicos si el homenaje fue erigido en ese lugar. Hasta el día de hoy, tal designación no está documentada para Scallabis cuyo único nombre oficial conocido es Scallabis Praesidium Iulium ${ }^{23}$. Por el contrario, en un pedestal dedicado al Genium y en varias sigillata, tejas y tuberías de plomo procedentes de la antigua Mérida, figuran las siglas CIAE - sin puntos separadores entre ellas ${ }^{24}$ - que podrían corresponder al título oficial Colonia Iulia Augusta Emerita ${ }^{25}$.

\section{C. POMPEIUS L.f. PAP. PRISCUS}

\section{Procedencia del epígrafe: Mérida \\ Referencias bibliográficas: $H A E, 2358 ; E R A E, 112$ \\ Cursus honorum, según orden de grabación: \\ $1^{\mathrm{o}}$ flamen coloniae \\ $2^{\mathrm{o}}$ duumuir \\ $3^{\text {o }}$ flamen prouinciae Lusitaniae}

Reconstrucción de la secuencia de ejercicio de los honores: segura (orden directo)

22 Restitución más convincente para J. Edmondson, $M M, 38$, 1997, p. 102, not. 51, porque explica que Capito haya sido honrado en Scallabis. En nuestra opinión, nada tiene de sorprendente que el flamen de Lusitania sea homenajeado en una ciudad de esta provincia, más cuando nos consta que la estatua fue erigida el año en que Capito era titular del sacerdocio. Recordemos la figura del flamen provincial salacense $L$. Cornelius L.f. Gal. Bocchus, a quien el ordo de Olisipo honró con la erección de una estatua en el municipio ( FE, 1999, 275), o a su pariente y también flamen de Lusitania L. Cornelius C.f. Bocchus, homenajeado en Tróia (CIL II, $5184=I R C P, 207)$.

23 NH, IV. 117.

24 R. Étienne-F. Mayet, 1984, p. 161-167.

25 Poco convincentes nos parecen el resto de propuestas de lectura. J. Álvarez de Buruaga, 1982, p. 6, descarta el desarrollo C(olonia) I(ulia) A(ugusta) E(merita) propuesto por J.-P. Bost, basándose en que el epíteto Iulia no aparece en otras fuentes. El autor propone desarrollar las abreviaturas del epígrafe que nos ocupa como Ci(uitatis) A(ugustae) E(meritae). Por su parte W. Trillmich, 1990, p. 299, not. 2, interpreta la I como abreviatura del término inmunis. 


\title{
4. CN. CORNELIUS Cn.f. PAP. SEVERUS
}

\author{
Procedencia del epígrafe: Mérida \\ Referencias bibliográficas: $A E, 1915,95 ; E R A E, 95$ \\ Cursus honorum, según orden de grabación: \\ $1^{\circ}$ aedilis \\ $2^{\mathrm{o}}$ duumuir \\ $3^{\text {o }}$ flamen Iuliae Augustae \\ $4^{\circ}$ praefectus fabrum
}

Reconstrucción de la secuencia de ejercicio de los honores: segura (orden directo)

El cursus protagonizado por Cn. Cornelius Cn. f. Pap. Seuerus tuvo que desarrollarse con posterioridad al año 14, puesto que fue Augusto quien dispuso en su testamento que Livia adoptase el nombre de Iulia Augusta ${ }^{26}$.

Aunque se viene tomando el año 29 como terminus de datación ante quem para la carrera de este ciudadano originario de Emerita Augusta $^{27}$, pensamos que no ha de descartarse datarla con posterioridad a la muerte de Iulia Augusta, siempre antes de que su nieto Claudio la proclamara Diua Augusta en el año $41^{28}$. Fue tras la muerte de Augusto cuando el culto tributado a Iulia Augusta se difundió tanto en Oriente como en Occidente, pero su muerte en absoluto significó que dejara de recibir honores divinos antes de integrarse en el panteón romano como diosa $^{29}$. La continuidad de esta devoción se habría producido de forma espontánea, tal vez impulsada por el tratamiento que el senado otorgó a la viuda de Augusto tras su muerte ${ }^{30}$, y encontraría mayor razón de

26 Reconociendo así la destacada posición de su esposa en la domus de la familia fundadora del Principado, R. Ma Cid López, Arys, 1, 1998, p. 146.

27 R. Étienne, 1958, p. 199, D. Fishwich, 1987, vol. I(1), p. 166, not. 105, LMRS, p. 171 y A. Caballos Rufino, 1998, p. 217.

28 Dión Casio, LX. 5. 2-3.

29 Mª D. Mirón Pérez, 1996, p. 56-57.

30 Recuérdese que los patres concedieron a Iulia Augusta extraordinarios honores, después de que sus intentos de decretar su divinización hubieran sido abortados por Tiberio. 
ser en Hispania, una de las provincias donde Livia había alcanzado enorme popularidad en vida ${ }^{31}$.

En todo caso el flaminado de Cn. Cornelius Cn.f. Pap. Seuerus confirma que Livia fue adorada por los emeritenses antes de ser divinizada, circunstancia que también se constata en Olisipo, donde $Q$. Iulius Q.f. Gal. Plotus (n. ${ }^{\circ}$ 6) también actuó como flamen Iuliae Augustae tras haber sido elegido flamen Germanici Caesaris.

5. M. AURELIUS C.f. GAL.

Procedencia del epígrafe: Beja

Referencias bibliográficas: CIL II, 49; IRCP, 236

Cursus honorum, según orden de grabación:

$1^{\mathrm{o}}$ duumuir

$2^{\mathrm{o}}$ flamen Tiberii Caesaris Augusti

$3^{\text {o }}$ praefectus fabrum

Reconstrucción de la secuencia de ejercicio de los honores: segura (orden directo)

\section{Q. IULIUS Q.f. GAL. PLOTUS}

Procedencia del epígrafe: Lisboa

Referencias bibliográficas: EOlis, 41; LMRS, 366

Cursus honorum, según orden de grabación:

$1^{\mathrm{o}}$ aedilis

$2^{\mathrm{o}}$ duumuir

$3^{\text {o }}$ flamen Germanici Caesaris

4ำ flamen Iuliae Augustae in perpetuum

Reconstrucción de la secuencia de ejercicio de los honores: segura (orden directo)

31 Véanse los testimonios que de su culto en las provincias hispanas recoge $\mathbf{M}^{\mathbf{a}}$ D. Mirón Pérez, 1996, p. 57-60. 
La datación que ofrece el cursus honorum protagonizado por $Q$. Iulius Q.f. Gal. Plotus aporta una información de gran intéres sobre la naturaleza y difusión del culto imperial en las ciudades de Lusitania.

Este personaje fue elegido flamen para encargarse de supervisar el culto que los olisiponenses tributaron a Germánico César en vida, de lo que se deduce que antes del año 19 un miembro vivo de la familia imperial era objeto de veneración en Olisipo y que su culto contaba con una organización sacerdotal en el ámbito municipal. En función de la cronología asignada a este flaminado, pensamos que también Iulia Augusta fue adorada en Olisipo antes de su muerte en el año 29, puesto que $Q$. Iulius Q.f. Gal. Plotus actuó como flamen Iuliae Augustae tras ocupar un sacerdocio que había obtenido con anterioridad al año 19.

La existencia de Cn. Cornelius Cn.f. Pap. Seuerus (n. ${ }^{\circ}$ 4), M. Aurelius C.f. Gal. (n. ${ }^{\circ}$ 5) y $Q$. Iulius $Q . f$. Gal. Plotus confirma que bajo el reinado de Tiberio algunos miembros vivos de la casa imperial fueron adorados colectivamente en ciudades de Lusitania: el emperador reinante en Pax Iulia, Germánico César en Olisipo y Iulia Augusta en Olisipo y, tal vez, en Emerita Augusta.

Esta constatación nos lleva a plantearnos si también la persona de Augusto fue adorada en las ciudades de Lusitania antes de que el senado decretara su divinización en el año 14, y si esta manifestación religiosa contó con una organización sacerdotal.

En el forum de Emerita Augusta se erigió un templo dedicado al culto imperial conocido en la actualidad como " Templo de Diana". Su construcción se emprendió entre los años finales del reinado de Augusto y el de Tiberio, siguiendo los modelos de la arquitectura tardorepublicana ${ }^{32}$. La similitud que presenta dicho edificio y el erigido en Barcino durante los últimos años del siglo I a.e. con el templo construido en el municipio de Ebora, llevan a R. Étienne a proponer una cronología similar también para éste último ${ }^{33}$. Otros lugares públicos de la capital de Lusitania también fueron utilizados para las celebraciones del culto imperial tributado al primer emperador. Tal fue el caso de una pequeña habitación ubicada en el teatro inaugurado en Emerita Augusta en el año 16-15 a.e., donde se rindió culto a Augusto

32 Sobre la localización y datación de este edificio pueden consultarse, entre otros, los trabajos de M. A. Bach, 1976, p. 203-206, J. L. de la Barrera Antón, 1984, p. 72-74, J. Mª Álvarez Martínez, 1991, p. 83-93 y X. Dupré, 1997, p. 158-160.

33 1996, p. 157-163. 
capite uelato. Esta práctica pervivía en época de Trajano, bajo cuyo reinado se construyó en el graderío inferior un sacrarium dedicado al culto imperial $^{34}$.

El inicio de la construcción de templos dedicados al culto imperial antes de la muerte y divinización de Augusto, hace pensar que ya eran elegidos flamines encargados de supervisarlo. Sin embargo, ninguna de las titulaturas de los sacerdotes hasta hoy conocidos en ciudades de Lusitania les relacionan con el culto a su persona antes del año 14.

No obstante, precisamente la temprana datación que ofrecen los sacerdocios relacionados con el culto tributado a miembros vivos de la familia julio-claudia es un indicio a considerar a favor de la implantación de cultos colectivos organizados en el ámbito cívico que tenían a Augusto como objeto de veneración. Bajo el reinado de su sucesor nos consta que ya eran elegidos flamines en Pax Iulia para supervisar el culto al emperador reinante (n. ${ }^{\circ}$ ). De igual modo, el epígrafe en el que es mencionado $Q$. Iulius $Q . f$. Gal. Plotus confirma que antes del año 19 estaba implantado y organizado en una ciudad de Lusitania un culto tributado a Germánico César y, posiblemente, a Iulia Augusta.

\section{7. [-] IUNIUS L.f. GAL. PHILO}

Procedencia del epígrafe: Alcácer do Sal

Referencias bibliográficas: IRCP, 186

Cursus honorum, según orden de grabación:

duumuir

ex d(ecreto) d(ecurionum) flamen Diui Augusti perpetuus

Reconstrucción de la secuencia de ejercicio de los honores: imprecisable

Aunque J. A. Delgado Delgado interpreta que la carrera fue grabada en orden directo ${ }^{35}$, el motivo que propició el homenaje nos hace dudar a la hora de considerar el duunvirato el primero de los honores recibidos.

34 W. Trillmich, Anas, 2-3, 1989-90, p. 87-102.

35 Conimbriga, 39, 2000, p. 119. 
En la cara opuesta a la que acoge la grabación del cursus, se precisó que [-] Iunius L. f. Gal. Philo había sido honrado [-ob memo/ra?]ndum $m$ [erit(um)?] / in rem p(ublicam) / [et] plebem suam / $d$ (ecreto) $\mathrm{d}$ (ecurionum). Si bien la restitución de la fórmula " $o b$ memorandum meritum" no es segura, el término res p(ublica) se lee con toda claridad. Este vocablo latino está haciendo alusión a la participación del homenajeado en el gobierno y administración del estado, es decir, a su actuación como duunviro. Los servicios prestados como magistrado y su buen hacer para con la plebe, animaron a uno de sus conciudadanos llamado Duronius [-] $f$. Gal. Modestus, a erigirle una estatua en suelo público que requirió la emisión de un decreto por el ordo decurionum.

8. [-]NIUS C.f. GALBA

Procedencia del epígrafe: Mérida

Referencias bibliográficas: $L M R S, 345$; J. C. Saquete Chamizo, 1997, p. 117 , n. ${ }^{\circ} 4$ y not. 436, lám. V. 2, p. 211

Cursus honorum, según orden de grabación:

$1^{\mathrm{o}}$ duumuir

$2^{\text {o }}$ [flamen D]iui Augusti

Reconstrucción de la secuencia de ejercicio de los honores: segura (orden directo)

J. C. Saquete Chamizo piensa que casi con seguridad [-]NIUS C. f. Galba habría sido receptor de la edilidad. Tras revisar la fotografía del epígrafe (fig. 4), no apreciamos resto alguno de la grabación de dicha magistratura.

\section{ANONYMUS}

Procedencia del epígrafe: Faião (freguesia de Terrugem, Sintra) Referencias bibliográficas: J. C. Ribeiro, AP, 7-10, 3.ํ s., 1974-77, p. 331-332

Cursus honorum, según orden de grabación: 


$$
\begin{aligned}
& {[-i I I ?] u(\text { ir })} \\
& \text { flam(en) Aug(ustalis) }
\end{aligned}
$$

Reconstrucción de la secuencia de ejercicio de los honores: duunvirato no seguro

A pesar de indicar la inseguridad en la restitución del duunvirato $^{36}$, J. A. Delgado Delgado acaba computando este testimonio entre las carreras en las que la máxima magistratura civil precede a un flaminado cívico.

Los honores fueron grabados sobre una de las caras de un bloque paralelepípedo muy deteriorado que, en opinión de J. C. Ribeiro, formaba parte de la fachada delantera de una construcción funeraria (fig. 5). Sólo se conservan fragmentariamente las cuatro líneas que constituían el final de la inscripción. La restitución del duunvirato únicamente se apoya en la identificación que el autor hace del rasgo derecho de una $V$, letra que precedería a la abreviatura del término flam(en) en la primera línea ${ }^{37}$. Se habrían perdido por completo la nomenclatura del difunto, tal vez la advocación a los Dioses Manes, así como los primeros honores que formaban el cursus, incluido el numeral II que junto con la $V$ constituiría la abreviatura $I I u(i r)$. En caso de aceptar tal restitución, habríamos de admitir una abreviatura para el duunvirato muy poco habitual en la epigrafía hispana ${ }^{38}$.

\section{L. PORCIUS L.f. GAL. HIMERUS}

\section{Procedencia del epígrafe: Alcácer do Sal \\ Referencias bibliográficas: $C I L$ II, $34=6894$; IRCP, 187 \\ Cursus honorum, según orden de grabación: \\ $1^{\mathrm{o}}$ duumuir \\ $2^{\mathrm{o}}$ praefectus pro duumuiro \\ 3ำ flamen Diuorum bis}

Reconstrucción de la secuencia de ejercicio de los honores: segura (orden directo)

36 Conimbriga, 39, 2000, p. 119.

37 AP, 7-10, 3. - s., 1974-77, p. 296-302.

38 J. C. Ribeiro, $A P, 7-10,3 .^{\text {a }}$ s., 1974-77, p. 326, not. 165, sólo encuentra un testimonio de la abreviatura $u($ ir $)(C I L$ II, 693). 


\section{1. [C.? IUL]IUS C.f. GAL. PEDO}

Procedencia del epígrafe: Beja

Referencias bibliográficas: $C I L$ II, 53; IRCP, 239

Cursus honorum, según orden de grabación:

duumuir

flamen Diuorum

Reconstrucción de la secuencia de ejercicio de los honores: imprecisable

De nuevo el motivo del homenaje suscita la duda a la hora de aceptar una grabación directa del cursus. En esta ocasión, la plebe de Pax Iulia homenajeó a uno de sus duunviros y sacerdotes "ob rem publica bene administratam et annonam inlata pecunia adiutam".

Como a [-] Iunius L.f. Gal. Philo (n. ${ }^{\circ}$ ), la plebe de su ciudad de origen agradeció a [C.? Iul]ius $C$. $f$. Gal. Pedo su doble buena actuación en beneficio de la comunidad como gestor de la res publica y como ciudadano altruista que realizó una aportación personal en metálico para cubrir el abastecimiento de grano.

Si bien [C.? Iul]ius C.f. Gal. Pedo pudo auxiliar a la annona no necesariamente cuando ocupaba el duunvirato, sus conciudadanos le homenajearon específicamente por su generosidad y por su labor como duunviro. Esta circunstacia deja abierta la posibilidad de que el último honor del cursus honorum que protagonizó en Pax Iulia haya sido la máxima magistratura civil y que el homenaje se realizara a la salida de dicho cargo.

\section{2. [-]O L. $[f($ ilio $)-F] E L I C I[O R I]$}

Procedencia del epígrafe: Faro

Referencias bibliográficas: $C I L$ II, $5141=I R C P, 8$

Cursus honorum, según orden de grabación:

flamen et IIuir Ossonob(ensi)

Reconstrucción de la secuencia de ejercicio de los honores: imprecisable 
Concordamos con J. A. Delgado Delgado ${ }^{39}$ cuando duda a la hora de determinar la secuencia de ejercicio de ambos honores, aunque no comprendemos por qué contabiliza esta carrera entre aquellas en las que el duunvirato precedió al flaminado.

\section{L. CO[RNELIUS - ]}

Procedencia del epígrafe: Alcácer do Sal

Referencias bibliográficas: IRCP, 188; FE, 1984, 40

Cursus honorum, según orden de ejercicio:

IIuir (duumuiro uel duumuir) [-]

flam[ini uel en - ]

Reconstrucción de la secuencia de ejercicio de los honores: flaminado no seguro

No está confirmado que el protagonista de este cursus honorum ocupara un flaminado cívico. La abreviatura del término flamen fue grabada en el inicio de la tercera línea, pudiendo corresponder tanto a un flaminado local como provincial, honor éste último que nos consta fue recibido por dos salacenses homónimos, los Lucii Cornelii Boc$c h{ }^{40}$. Creemos que lo correcto desde el punto de vista metodológico sería incluir a este sacerdote entre los flamines cívicos incerti.

\section{UMMIDIUS}

Procedencia del epígrafe: Mérida

Referencias bibliográficas: $L M R S, 338$

Cursus honorum, según orden de grabación:

IIuir flamen

Reconstrucción de la secuencia de ejercicio de los honores: imprecisable

39 Conimbriga, 39, 2000, p. 119.

40 Tal como figura en los siguientes documentos epigráficos con ellos relacionados: CIL II, 35 = IRCP , 185, FE, 1996, 235, FE, 1999, 275 y CIL II, $5184=I R C P$, 207. 
Ambos honores fueron grabados en una misma línea sobre un sillar del anfiteatro de Emerita Augusta, junto al gentilicio Ummidius.

Una vez revisada la documentación, pensamos que para obtener conclusiones de mayor validez a la hora de determinar si el flaminado cívico precede mayoritariamente al duunvirato en los cursus identificados en Lusitania, deberían excluirse seis de los catorce analizados. Su exclusión estaría justificada, bien por no estar confirmada la convivencia de la máxima magistratura civil y de un sacerdocio cívico (n. ${ }^{\circ} 9,13$ ), bien por no poder determinar con seguridad la secuencia de ejercicio de ambos honores $\left(\mathrm{n} .^{\circ} 7,11,12,14\right)$.

El dossier epigráfico a valorar quedaría reducido a ocho epígrafes. Sobre dos de ellos fueron grabadas carreras que comenzaron con la recepción de un flaminado cívico seguida del duunvirato $\left(n .^{\circ} 1,3\right)$, mientras en los seis cursus restantes es la magistratura civil la que precede al flaminado $\left(\mathrm{n} .^{\circ} 2,4,5,6,8,10\right)$. Por tanto, podremos concluir, a lo sumo, que el flaminado cívico podía ser obtenido tanto con anterioridad como con posterioridad al duunvirato, siendo más frecuente que los honorati desempeñaran funciones en el ámbito civil antes que en el religioso. Realmente la diferencia en términos numéricos entre los documentos en que se apoyan ambas posibilidades no es relevante, pudiendo incluso explicarse por el azar en los hallazgos epigráficos. Resulta interesante observar que no se aprecia diferencia alguna entre la proyección conquistada por aquellos honorati que obtuvieron un flaminado antes de ocupar el duunvirato, y los que iniciaron su cursus como duunviros. Tanto [-] M.f. Ser. Modestus (n. $\left.{ }^{\circ} 1\right)$ y C. Pompeius L. f. Pap. Priscus (n. ${ }^{\circ}$ ), ambos flamines antes que duunviros en Emerita Augusta, acabaron conquistando el flaminado provincial, lo mismo que Capito, (n. ${ }^{\circ}$ ), duunviro antes que flamen también en la capital de Lusitania.

Una cuestión aún más decisiva que subyace en la metodología utilizada por J. A. Delgado Delgado es que se fundamenta en que "la posición del flaminado respecto a los otros cargos públicos en las carreras es una cuestión importante para determinar el prestigio y la importancia del sacerdocio" ${ }^{41}$. En este sentido, convendría recordar que en las carreras públicas que se desarrollan en las ciudades de

41 Conimbriga, 39, 2000, p. 120. 
Hispania, únicamente existe un orden jerárquico en la recepción de las magistraturas civiles. No hay duda alguna de que el duunvirato era la magistratura suprema dentro del sistema colegial, como prueba la superioridad de los duumuiri iure dicundo sobre cuestores y ediles, al tener potestad para vetar las decisiones tomadas por éstos ${ }^{42}$.

Excluyendo edilidad, cuestura y duunvirato - cuya jerarquía al no ser siempre respetada ${ }^{43}$ propició la intervención de ciertos emperadores para intentar reconducir la situación ${ }^{44}$ - nada permite suponer que los honores obtenidos en el ámbito cívico en un momento dado eran de mayor prestigio e importancia que los que habían sido recibidos anteriormente. Cada cursus honorum constituye una trayectoria única en sí misma, sin que se ajuste a una sucesión jerárquica de cargos comparable a la del rígido cursus senatorius o a las militiae equestris, secuencia que en ambos casos era fijada por el estado.

Podemos llegar a distinguir cuáles eran los recorridos más habituales en la recepción de los honores civiles y religiosos, pero no establecer una jerarquía de prestigio entre ellos. En relación con esta cuestión, hemos podido comprobar que en Lusitania, los honorati con aspiraciones de promocionar socialmente no protagonizan verdaderas "carreras", sino que trataron de acumular magistraturas civiles y sacerdocios. Esto se explica porque la acumulación de honores podía conducirles a conquistar una proyección más allá del ámbito cívico. Ésta podía materializarse obteniendo el flaminado provincial o mediante el ingreso en el ordo equester a través de la prefectura de los trabajadores manuales, lo que dejaba abiertas las puertas de la carrera ecuestre y del senado a los descendientes, como en el caso del magistrado y flamen emeritense Cn. Cornelius Cn.f. Pap. Seuerus ${ }^{45}$.

¿ Representó el flaminado cívico el colofón de diez de las once carreras locales conocidas por documentos epigráficos hallados en Lusitania, tal como constata J. A. Delgado Delgado en su estudio?

42 Lex Irn., 27.

43 Así lo ha comprobado L. A. Curchin, LMRS, p. 16 y 21-57 en las carreras protagonizadas por los magistrados de Hispania. Sobre la Bética y Lusitania, véanse los trabajos anteriores de J. F. Rodríguez Neila, 1978, p. 203-210 y J. de Francisco Martín, MHA, 1, 1977, p. 227-245 y 1989 (2.․ ed. 1996), p. 108-140.

44 Dig., LIV. 4. 11. pr. y 14.3.

45 M. González Herrero, cap. II y III (en prensa, formato CD-R). 
En nuestra opinión, la correcta metodología para determinar cuál es el cargo con el que culminan los cursus locales, consistiría en analizar exclusivamente carreras concluidas. Por tanto, sólo habrían de considerarse las que figuran sobre epitafios y homenajes póstumos, quedando excluidas las inscripciones cuyo carácter no se puede determinar, así como las intervenciones oficiales de los honorati, los homenajes que reciben en vida, o los epígrafes que nos dan a conocer los actos de evergetimo ob liberalitatem que protagonizaron. Su exclusión se justifica porque estos epígrafes nos dan conocer los honores recibidos hasta un determinado momento, de manera que desconocemos si la actividad pública de los personajes continuó.

En la siguiente tabla figuran los nombres de aquellos honorati elegidos flamines cívicos en Lusitania, sin que superaran en su promoción el ámbito urbano. Nótese que, con excepción de dos que actuaron como pontifices, el resto también ocuparon el duunvirato, de manera que sus carreras ya han sido comentadas en estas páginas. Incluimos además la referencia bibliográfica del epígrafe más accesible y la indicación del carácter de la inscripción. 


\section{CARRERAS LOCALES DE LAS QUE FORMA PARTE UN FLAMINADO}

\begin{tabular}{|c|c|c|}
\hline NOMBRE & REFERENCIA & $\begin{array}{l}\text { CARÁCTER DE } \\
\text { LA INSCRIPCIÓN }\end{array}$ \\
\hline $\begin{array}{l}\text { Q. IULIUS Q.f. GAL. PLOTUS } \\
\text { N. }{ }^{\circ} 6\end{array}$ & EOlis., 41 & $\begin{array}{l}\text { Pedestal de estatua } \\
\text { [Homenaje en vida] }\end{array}$ \\
\hline $\begin{array}{l}\text { [L.?] IUNIUS L.f. GAL. PHILO } \\
\text { N. } 7\end{array}$ & $\operatorname{IRCP}, 186$ & $\begin{array}{l}\text { Pedestal de estatua } \\
\text { [Homenaje en vida] }\end{array}$ \\
\hline $\begin{array}{l}{[-] N I U S C . f . G A L B A} \\
\text { N. }{ }^{\circ} 8\end{array}$ & $L M R S, 345$ & $\begin{array}{l}\text { Imprecisable si es } \\
\text { epitafio u homenaje }\end{array}$ \\
\hline $\begin{array}{l}\text { ANONYMUS } \\
\text { N. }{ }^{\circ} 9\end{array}$ & $\begin{array}{l}\text { J. C. Ribeiro, } A P, 7-10, \\
\text { 3. }{ }^{\text {a s., }} \text { 1974-77, p. 331-332 }\end{array}$ & Funerario \\
\hline $\begin{array}{l}\text { L. PORCIUS L.f. GAL. HIMERUS } \\
\text { N. }{ }^{\circ} 10\end{array}$ & IRCP, 187 & $\begin{array}{l}\text { Homenaje en vida } o b \\
\text { merita por patrocinio de la } \\
\text { plebs. El magistrado asu- } \\
\text { mió los gastos del titulus }\end{array}$ \\
\hline $\begin{array}{l}{[C . ? \text { IUL]IUS C.f. GAL. PEDO }} \\
\text { N. }{ }^{\circ} 11\end{array}$ & IRCP , 239 & $\begin{array}{l}\text { Homenaje en vida cos- } \\
\text { teado por suscripción } \\
\text { popular }\end{array}$ \\
\hline $\begin{array}{l}{[-] O L .[f .-F] E L I C I[O R I]^{46}} \\
\text { N. }{ }^{\circ} 12\end{array}$ & $I R C P, 8$ & $\begin{array}{l}\text { Homenaje póstumo de } \\
\text { cuatro amici }\end{array}$ \\
\hline $\begin{array}{l}\text { L. CO }[\text { RNELIUS - }] \\
\text { N. }{ }^{\circ} 13 \\
\text { FLAMEN CÍVICO INCERTUS }\end{array}$ & $\operatorname{IRCP}, 188$ & Imprecisable \\
\hline $\begin{array}{l}\text { UMMIDIUS } \\
\text { N. }{ }^{\circ} 14\end{array}$ & LMRS, 338 & $\begin{array}{l}\text { Imprecisable. Nombre } \\
\text { y cursus en nominativo } \\
\text { grabados sobre un sillar } \\
\text { del anfiteatro }\end{array}$ \\
\hline ACILIANUS & $\operatorname{IRCP}, 343$ & $\begin{array}{l}\text { Epitafio costeado por } \\
\text { suscripción popular }\end{array}$ \\
\hline ANONYMUS & IRCP, 242 & Imprecisable \\
\hline
\end{tabular}

46 Recogemos la restitución de la nomenclatura en caso dativo. 
Únicamente son tres las inscripciones con carácter funerario en las que se recuerda la actividad de flamines cívicos lusitanorromanos: la construcción en la que se grabó el cursus del flamen Augustalis enterrado en la zona oeste de los agri de Olisipo (n. ${ }^{\circ}$ 9), el homenaje al [amicus ben]emeren[tissimo e]t pientissimo patrocinado por cuatro amici de un flamen et duumuir en Ossonoba (n. $\left.{ }^{\circ} 12\right)^{47}$ y el pésimamente conservado epitafio de un pontífice y flamen de Pax Iulia (IRCP, 343).

De acuerdo con lo expuesto, pensamos que no existe apoyo documental para sostener que prácticamente la totalidad de las carreras locales que se desarrollaron en ciudades de la provincia de Lusitania culminaron con un flaminado cívico.

\section{REFERENCIAS BIBLIOGRÁFICAS}

Álvarez de Buruaga, J. (1982) - "Acerca del nombre de la Colonia Augusta Emerita", Museos, 1, p. 5-9.

Álvarez MartíneZ, J. Mª (1991) - La ciudad romana de Mérida (Cuadernos de Arte Español 6). Madrid.

BACH, M. A. (1976) - "La topografía de Augusta Emerita" en Symposion de Ciudades Augústeas, vol. 1, Zaragoza, p. 203-206.

Barrera Antón, J. L. de la (1984) - Los capiteles romanos de Mérida. Badajoz. Caballos Rufino, A. (1998) - "Los equites y la dinámica municipal de la Lusitania. I: Catálogo prosopográfico" en El proceso de municipalización en la Hispania romana. Contribuciones para su estudio, Valladolid, p. 205-233.

CID LóPEZ, R. M" (1998) - "Livia uersus Diua Augusta. La mujer del príncipe y el culto imperial", Arys, 1, p. 139-155.

CRUZ, Mª das D. G. da (1986) - "A propósito de uma inscrição honorífica do Museu de Santarém”, Arqueologia, 14, p. 115-121.

CurChIN, L. A. (1990) - The Local Magistrates of Roman Spain. Toronto. [LMRS] Delgado Delgado, J. A. (2000) - "Los sacerdotes de rango local de la provincia romana de Lusitania", Conimbriga, 39, p. 107-152.

DUPRÉ, X. (1997) - "El foro en las provincias hispánicas" en Hispania Romana. Desde tierra de conquista a provincia del Imperio, Roma, p. 158-160.

Edmondson, J. (1997) - "Two dedications to Diuus Augustus and Diua Augusta from Augusta Emerita and the early development of the imperial cult in Lusitania re-examined", $M M, 38$, p. 89-105.

47 Tal como hemos expuesto, la secuencia de ejercicio de los honores es imprecisable, de manera que no está confirmado que culminara su carrera con el sacerdocio. 
ÉTIENNE, R. (1958) - Le Culte Impérial dans la péninsule ibérique d'Auguste à Dioclétien (BEFAR 191). París.

ÉTIENNE, R. (1996) - "Du nouveau sur les débuts du culte impérial municipal dans le péninsule ibérique" en Subject and Ruler: The Cult of the Ruling Power in Classical Antiquity, JRA (Suplementary Series 17), p. 153-163.

ÉtIENNE, R. - MAYET, F. (1984) - "La dénomination antique de Merida", Homenagem a D. D. de Pinho Brandão, Oporto, p. 159-172.

Fishwick, D. (1987) - The Imperial Cult in the Latin West. Studies in the Ruler Cult of the Western Provinces of the Roman Empire (EPRO 108). 2 vols. Leiden.

FranCISCO MARTín, J. de (1977) - "Los magistrados municipales en Lusitania durante el Alto Imperio", $M H A, 1$, p. 227-245.

FranCISCO MARTíN, J. de 1989 (2.. ed. 1996) - Conquista y romanización de Lusitania. Salamanca.

GonZÁlez Herrero, M. (2002) - "Contribución al estudio prosopográfico de los equites lusitanorromanos: el cursus honorum protagonizado por el tribuno Lucius Cornelius Lucii filius Galeria Bocchus", Aquila Legionis, 2, p. 33-57.

GonZÁlez Herrero, M. (en prensa) - La promoción social de las elites del poder lusitanorromanas y su presencia en los círculos dirigentes de Roma. Siglos I-III. Oviedo (en curso de publicación por el Servicio de Publicaciones de la Universidad de Oviedo con el ISBN: 84-8317-261-5, formato CD-R).

JACQUES, F. (1984) - Le privilège de la liberté. Politique impériale et autonomie municipale dans les cités de l'Occident romain (161-244) [Coll. École Française de Rome 76]. París.

Mirón PéreZ, Ma D. (1996) - Mujeres, religión y poder: el culto imperial en el Occidente mediterráneo. Granada.

RIBEIRO, J. C. (1974-77) - "Três novos monumentos epigráficos da época romana pertencentes à la Zona Oeste do Município Olisiponense", $A P$, 7-10, 3.․ s., p. 281-329.

Rodríguez NeILA, J. F. (1978) - "Observaciones en torno a las magistraturas municipales de la Bética romana", Actas del Primer Congreso de Historia de Andalucía (Córdoba 1976), Córdoba, p. 203-210.

Salas Martín, J. (1987) - "Nuevas anotaciones a la epigrafía romana de Extremadura", Veleia, 4, p. 127-143.

Saquete Chamizo, J. C. (1997) - Las elites sociales de Augusta Emerita (Cuadernos Emeritenses 13). Mérida.

Thomas, I. (1996) - Origine et commune patrie. Étude de droit public romain (89 av. J.C.-212 ap. J.C.). Roma.

Trillmich, W. (1989-90) - "Un sacrarium del culto imperial en el Teatro de Mérida", Anas, 2-3, p. 87-102.

Trillmich, W. (1990) - "Colonia Augusta Emerita. Die Hauptstadt von Lusitanien", Stadtbild und Ideologie: Die Monumentalisierung hispanischer Städte zwischen Republik und Kaiserzeit. Kolloquium (Madrid, 19-23 oktober 1987), Munich, p. 299-318. 


\section{CORPORA EPIGRÁFICOS CITADOS EN EL TEXTO}

AE - L'Année Épigraphique

CIL - HÜBNER, E. (1869 y 1892) - Corpus inscriptionum latinarum, vol. II: Inscriptiones Hispaniae Latinae. Supplementum. Berlín.

EOlis. - Silva, A. V. da (1944) - Epigrafía de Olisipo. Subsídios para a História da Lisboa Romana. Lisboa.

ERAE - GARCÍA IGLESIAS, L. (1973) - Epigrafía romana de Augusta Emerita. Tesis doctoral inéd. Madrid.

FE - Ficheiro Epigráfico

HAE - Hispania Antiqua Epigraphica

ILER - VIVES, J. (1970) - Inscripciones latinas de la España romana. Barcelona

ILS - Dessau, H. (ed.) (1962) - Inscriptiones latinae selectae. 3 vols. Berolini: Apud Weidmannus.

IRCP - EnCARnaÇão, J. d' - Inscrições romanas do conventus Pacensis. Subsídios para o estudo da romanização. Coimbra.

RAP - GARCIA, J. M. (1991) - Religiões antigas de Portugal. Aditamentos e observações as "Religiões da Lusitânia" de J. Leite de Vasconcelos. Fontes epigráficas. Lisboa.

\section{EDICIONES DE FUENTES LITERARIAS Y JURÍDICAS CITADAS EN EL TEXTO}

\section{Dión Casio}

CARY, E. [Traducción], Dio's Roman History. Ed.: Loeb Classical Library, Londres, 1927 (reimp. 1982).

\section{Digesto}

Ors, A. D' et alii, El Digesto de Justiniano. Tomo I: Constituciones preliminares y Libros I-XXX, 1968. Tomo II: Libros XX-XXXVI, 1972. Tomo III: Libros XXXVII-XL, 1975. Ed.: Aranzadi, Pamplona.

\section{Lex Irnitana}

Fernández, F. - Amo. M. del, La Lex Irnitana y su contexto arqueológico, Sevilla, 1990

\section{Lex Tarraconensis}

Crawford, M. H., ed. Roman Statutes, Londres, 1996.

\section{Lex Ursonensis}

La Lex Ursonensis, Studia Historica (Historia Antigua), 15, 1997.

\section{Plinio el Viejo}

Warmington, E. H. [Traducción], Pline L'Ancien. Histoire Naturelle. Ed.: Loeb Classical Library, Londres, 1967-69. 


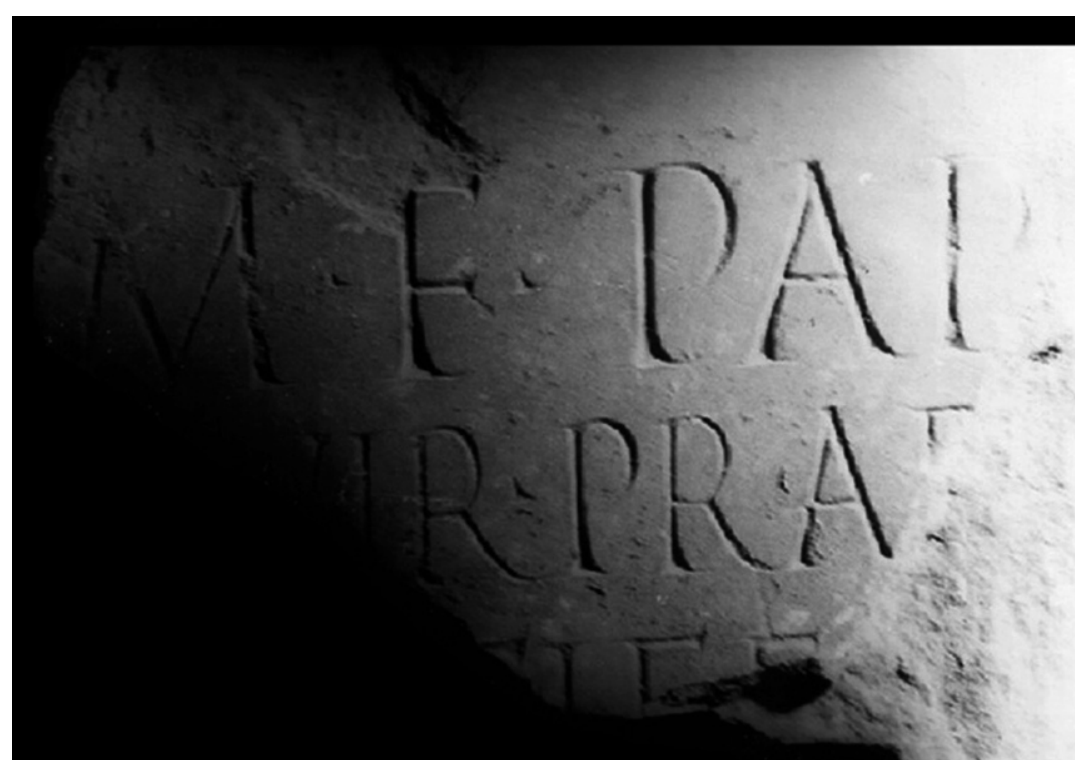

FIG. 1

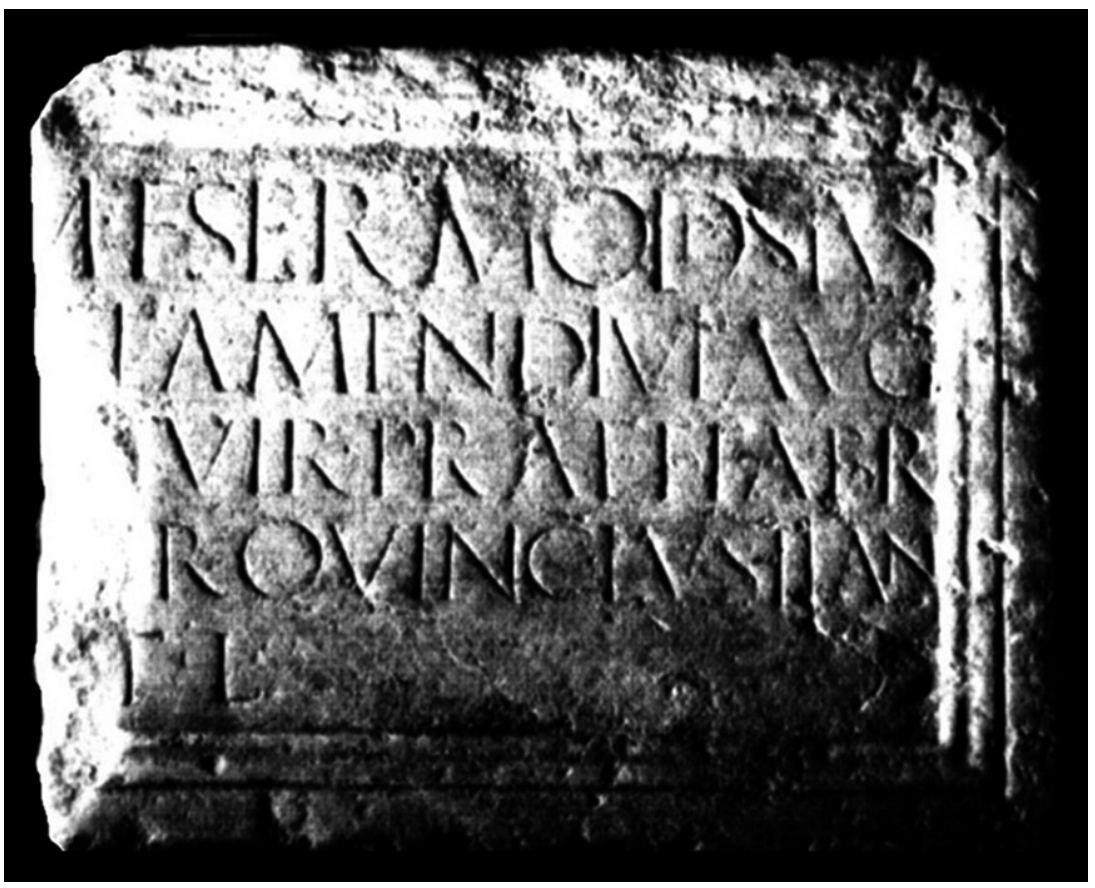

FIG. 2 

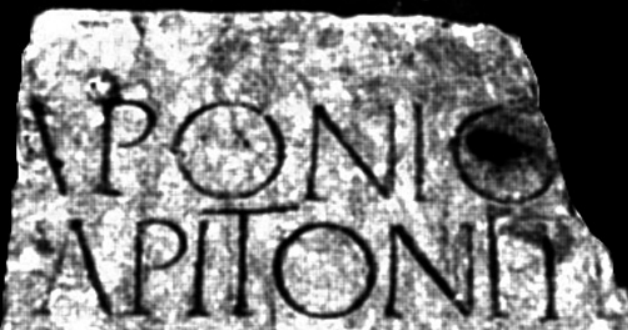

(a) 1.2 Vo WFEABRVM MNC(0) MIIPAOWW

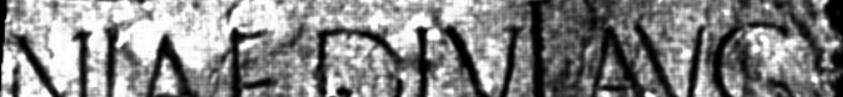

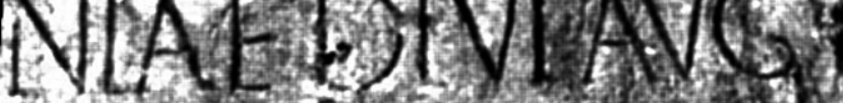

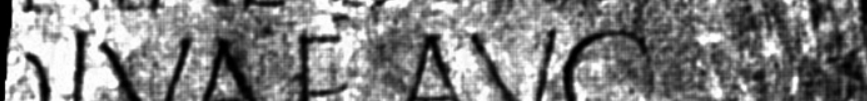

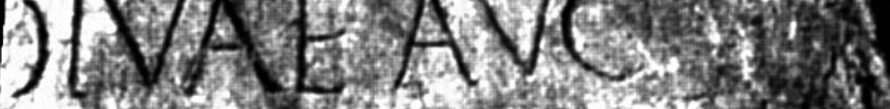

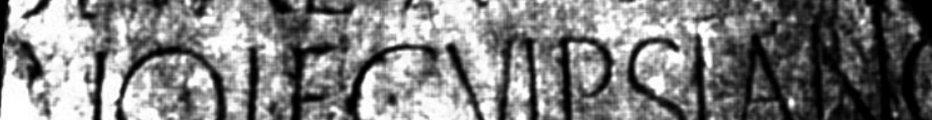

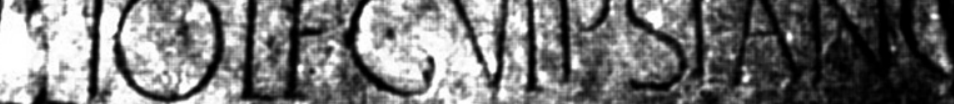
2,250

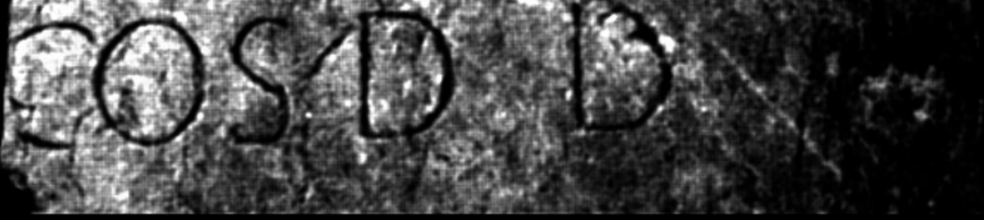




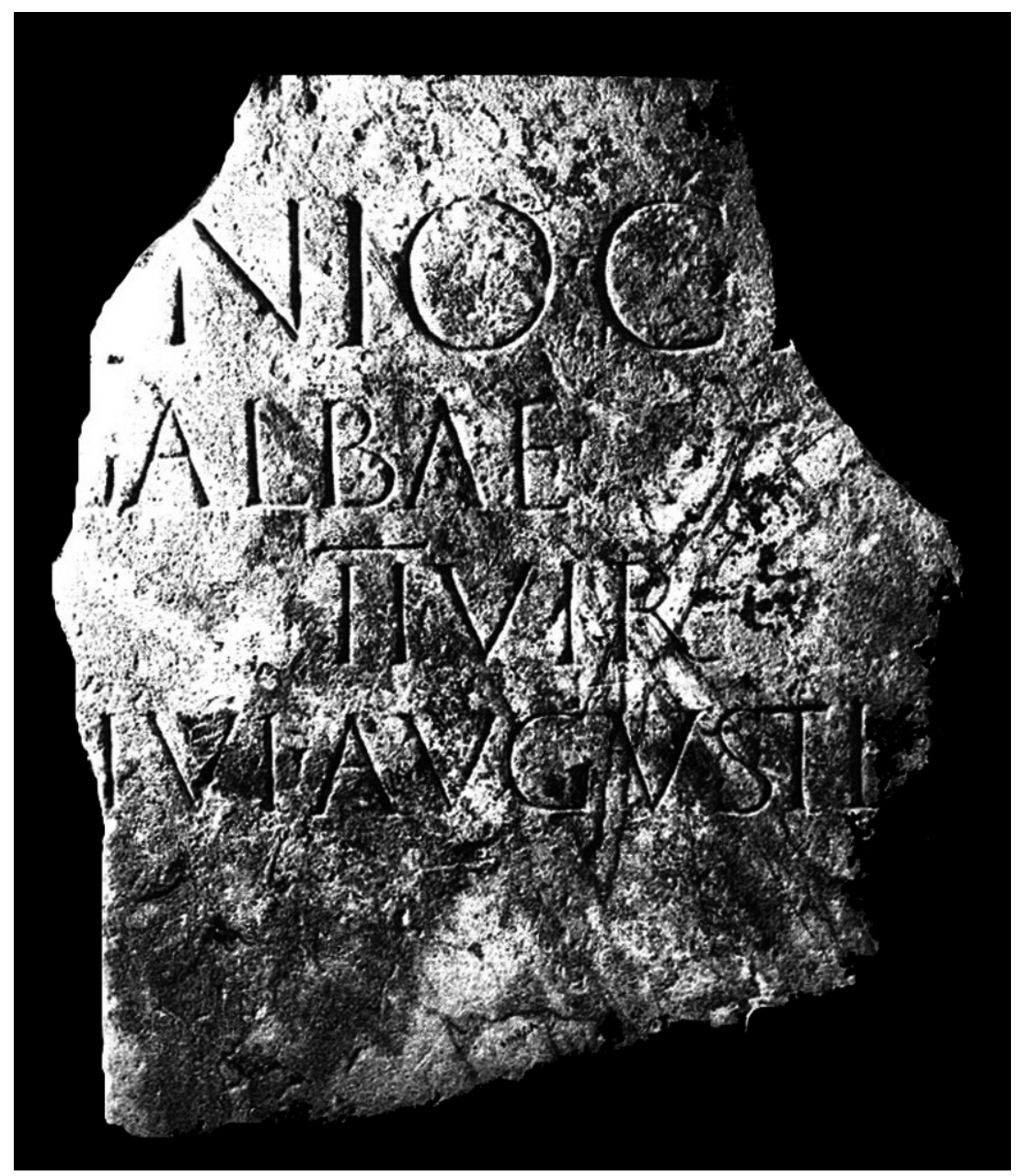

FIG. 4 


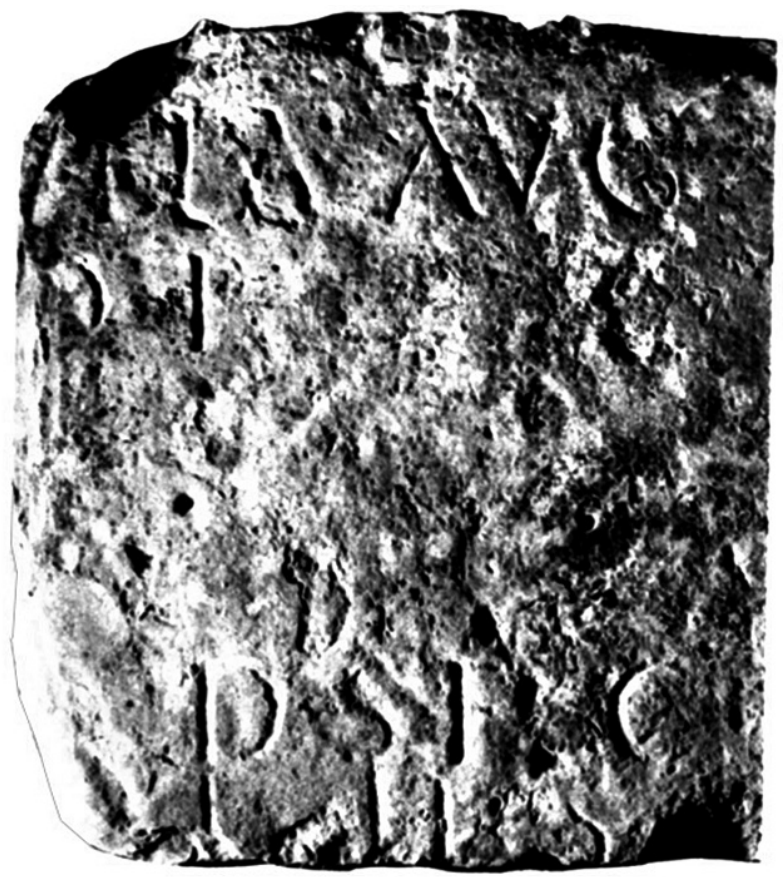

FIG. 5
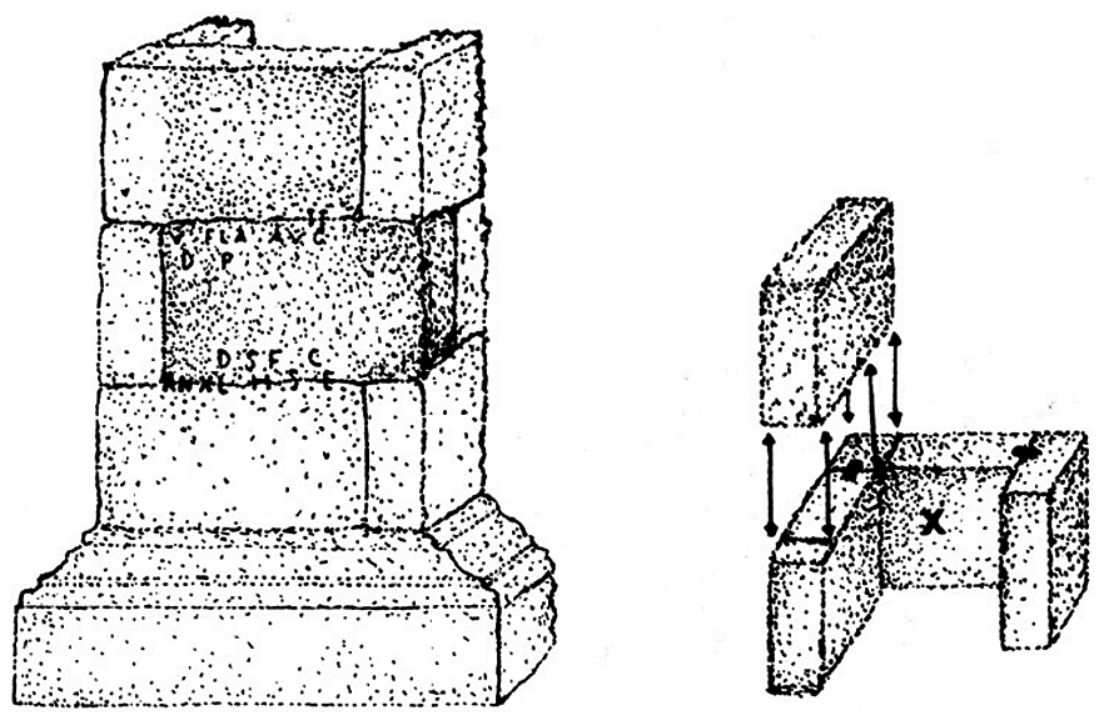

FIG. 6 